\title{
Robust All-Carbon Molecular Junctions on Flexible or Semi-Transparent Substrates Using "Process-Friendly" Fabrication
}

\author{
Amin Morteza Najarian ${ }^{1,2}$, Bryan Szeto $^{2}$, Ushula M. Tefashe ${ }^{1,2}$ Richard L. McCreery ${ }^{1,2 \dagger}$ \\ ${ }^{1}$ Department of Chemistry \\ University of Alberta \\ Canada,T6G 2R3 \\ ${ }^{2}$ National Institute for Nanotechnology \\ National Research Council Canada \\ Canada, T6G 2G2 \\ ${ }^{\dagger}$ corresponding author \\ Tel.: 780-641-1760 \\ Email: richard.mccreery@ualberta.ca
}

\section{Contents:}

1. Introduction

2. Fabrication

2.1 Bottom contact fabrication

2.2 Molecular layer grafting

2.2.1 PPF modification

2.2.2 $\mathrm{Cr} / \mathrm{Au} / \mathrm{eC}$ modification

2.2.3 $\mathrm{Cr} / \mathrm{Au}$ modification

2.3 Top contact deposition

3. Carbon electrode characterization

3.1 Raman Spectroscopy

3.2 XPS Spectroscopy

4. Electrical measurement

4.1 Two- and Four-wire mode measurement

4.2 Arrhenius plot for $\mathrm{eC} / \mathrm{AQ} / \mathrm{eC}$ junction

5. Statistics

6. Integrated photolithographic design 


\section{Introduction}

This supplementary information provides additional details on the fabrication process, experimental conditions, and electrode characterization. The detailed information is included to provide additional support for stated conclusions in the main text and experimental details allowing external research groups to reproduce the reported results.

\section{Fabrication}

Cross-bar molecular junction fabrication has three main steps: bottom contact fabrication, molecular layer grafting, and top contact deposition.

\subsection{Bottom contact fabrication}

The Au/eC substrate Bottom electrode was fabricated by electron beam deposition of $3 \mathrm{~nm}$ $\mathrm{Cr}$ (at $0.03 \mathrm{~nm} / \mathrm{s}$ ), $15 \mathrm{~nm} \mathrm{Au}($ at $0.03 \mathrm{~nm} / \mathrm{s}$ ) and $10 \mathrm{~nm}$ of eC (at $<0.01 \mathrm{~nm} / \mathrm{s}$ ). Beam current was adjusted during deposition of $\mathrm{eC}$ to maintain the rate at $<0.01 \mathrm{~nm} / \mathrm{s}$ (determined with quartz microbalance). Au purity was $99.99 \%$ and carbon source was $3 \mathrm{~mm}$ diameter spectroscopically pure graphite rods (SPI Supplies, PA) in a graphite crucible. Deposition was carried out using a physical shadow mask with four parallel $0.25 \mathrm{~mm}$ wide lines (shown Figure 1 of main text). Ebeam chamber pressure was kept lower than $4 \times 10^{-5}$ Torr throughout the deposition.

PPF electrode fabrication is described in detail elsewhere ${ }^{1}$. Briefly, positive photoresist (AZ 4330) was spun onto each sample, followed by a soft bake at $80{ }^{\circ} \mathrm{C}$ and then photolithography was carried out with a UV exposure. Development was done in a 1:3 dilution of AZ developer:water. Substrates with photoresist features were pyrolyzed in a 1-inch tube furnace by heating under a flow of forming gas $\left(5 \% \mathrm{H}_{2}\right.$, balance $\left.\mathrm{N}_{2}\right)$ to $1050{ }^{\circ} \mathrm{C}$ for 1 hour. After cooling in flowing forming gas, the PPF surface consists of $\mathrm{sp}^{2}$ carbon similar to glassy carbon with RMS roughness lower than $0.5 \mathrm{~nm}$. 


\subsection{AQ molecular layer grafting}

A conventional three-electrode electrochemical cell with $\mathrm{Ag} / \mathrm{Ag}^{+}$electrode as reference and Pt wire as a counter electrode was used for electrochemical grafting of a molecular layer on the surface of both the $\mathrm{Au} / \mathrm{eC}$ and PPF substrates. The solution was $1 \mathrm{mM}$ Anthraquinone diazonium fluoroborate dissolved in acetonitrile containing $0.1 \mathrm{M}$ tetrabutylammonium hexafluorophosphate $\left(\mathrm{TBAPF}_{6}\right)$ as supporting electrolyte. The thickness of grafted molecular layer was controlled by sweeping the potential from $0.4 \mathrm{~V}$ to $-0.6 \mathrm{~V}\left(v s . \mathrm{Ag} / \mathrm{Ag}^{+}\right)$at $50 \mathrm{mV} / \mathrm{s}$ for repeated cycles. After modification, the sample was rinsed with acetonitrile and dried using a stream of nitrogen. Measurement of molecular layer thickness was done using AFM, using the same procedure described in the supplementary data of a previous report ${ }^{2}$. Electrochemical parameters used for deposition of molecular layers on the surface of each electrode are listed in Table S1, S2, and S3.

\subsubsection{PPF modification with AQ}

The parameters used for grafting of molecular layer on the surface of PPF are listed in Table S1 and corresponding cyclic voltammograms are shown in Figure S1.

Table S1. Electrochemical parameters for grafting Anthraquinone molecular layer on the surface of PPF

\begin{tabular}{|c|c|c|c|c|}
\hline $\begin{array}{c}\text { Anthraquinone } \\
\text { Grafting }\end{array}$ & $\begin{array}{c}\text { Sweep range } \\
(\mathrm{E} \text { vs. Ag/Ag }\end{array}$ & $\begin{array}{c}\text { No. of } \\
\text { cycles }\end{array}$ & $\begin{array}{c}\text { Scan rate } \\
(\mathrm{mV} / \mathrm{s})\end{array}$ & $\begin{array}{c}\text { Thickness } \\
(\mathrm{nm})\end{array}$ \\
\hline Sample 1 & $0.4-(-0.20)$ & 6 & 50 & 2.2 \\
\hline Sample 2 & $0.4-(-0.25)$ & 6 & 50 & 2.9 \\
\hline Sample 3 & $0.4-(-0.30)$ & 6 & 50 & 3.4 \\
\hline Sample 4 & $0.4-(-0.40)$ & 8 & 50 & 3.9 \\
\hline Sample 5 & $0.4-(-0.50)$ & 8 & 50 & 4.3 \\
\hline Sample 6 & $0.4-(-0.55)$ & 8 & 50 & 5.5 \\
\hline
\end{tabular}




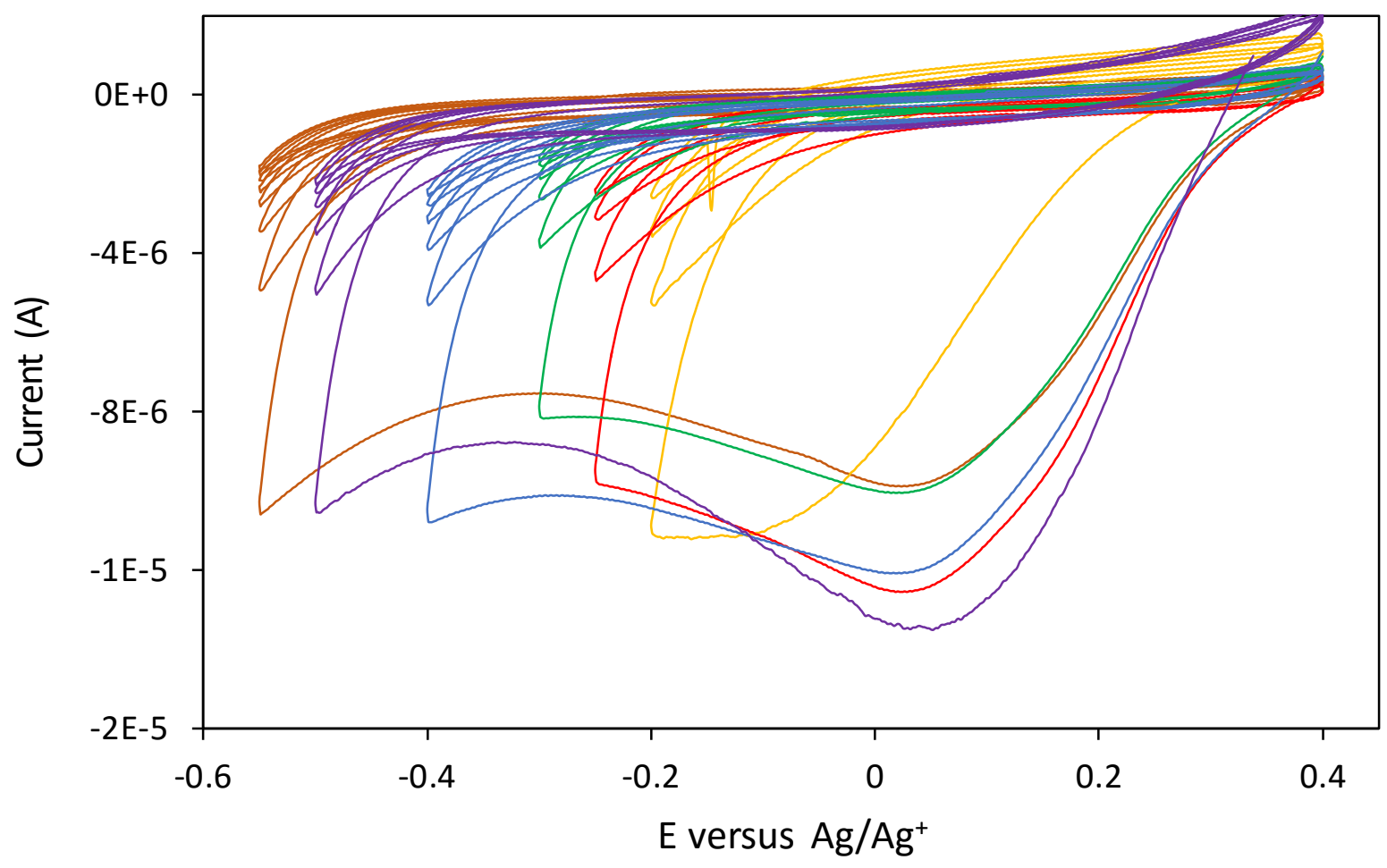

Figure S1. Cyclic voltammogram of reduction of AQ diazonium ion on PPF.

\subsection{2 $\mathrm{Cr} / \mathrm{Au} / \mathrm{eC}$ modification}

The parameters used for grafting of molecular layer on a $\mathrm{Cr} / \mathrm{Au} / \mathrm{eC}$ electrode are listed in Supplementary Table S2 and corresponding cyclic voltammograms are shown in Figure S2. 
Table S2. Anthraquinone grafting parameters for $\mathrm{Cr}_{3} / \mathrm{Au}_{15} / \mathrm{eC}_{10}$

\begin{tabular}{|c|c|c|c|c|}
\hline $\begin{array}{c}\text { Anthraquinone } \\
\text { Grafting }\end{array}$ & $\begin{array}{c}\text { Sweep range }(\mathrm{E} \\
\text { vs. Ag/Ag })\end{array}$ & $\begin{array}{c}\text { No. of } \\
\text { cycles }\end{array}$ & $\begin{array}{c}\text { Scan rate } \\
(\mathrm{mV} / \mathrm{s})\end{array}$ & $\begin{array}{c}\text { Thickness } \\
(\mathrm{nm})\end{array}$ \\
\hline Sample 1 & $0.4-(-0.30)$ & 6 & 50 & $2.3 \pm 0.25$ \\
\hline Sample 2 & $0.4-(-0.35)$ & 6 & 50 & $2.9 \pm 0.35$ \\
\hline Sample 3 & $0.4-(-0.45)$ & 6 & 50 & $3.8 \pm 0.27$ \\
\hline Sample 4 & $0.4-(-0.55)$ & 6 & 50 & $4.5 \pm 0.38$ \\
\hline Sample 5 & $0.4-(-0.60)$ & 8 & 50 & $5.1 \pm 0.32$ \\
\hline
\end{tabular}

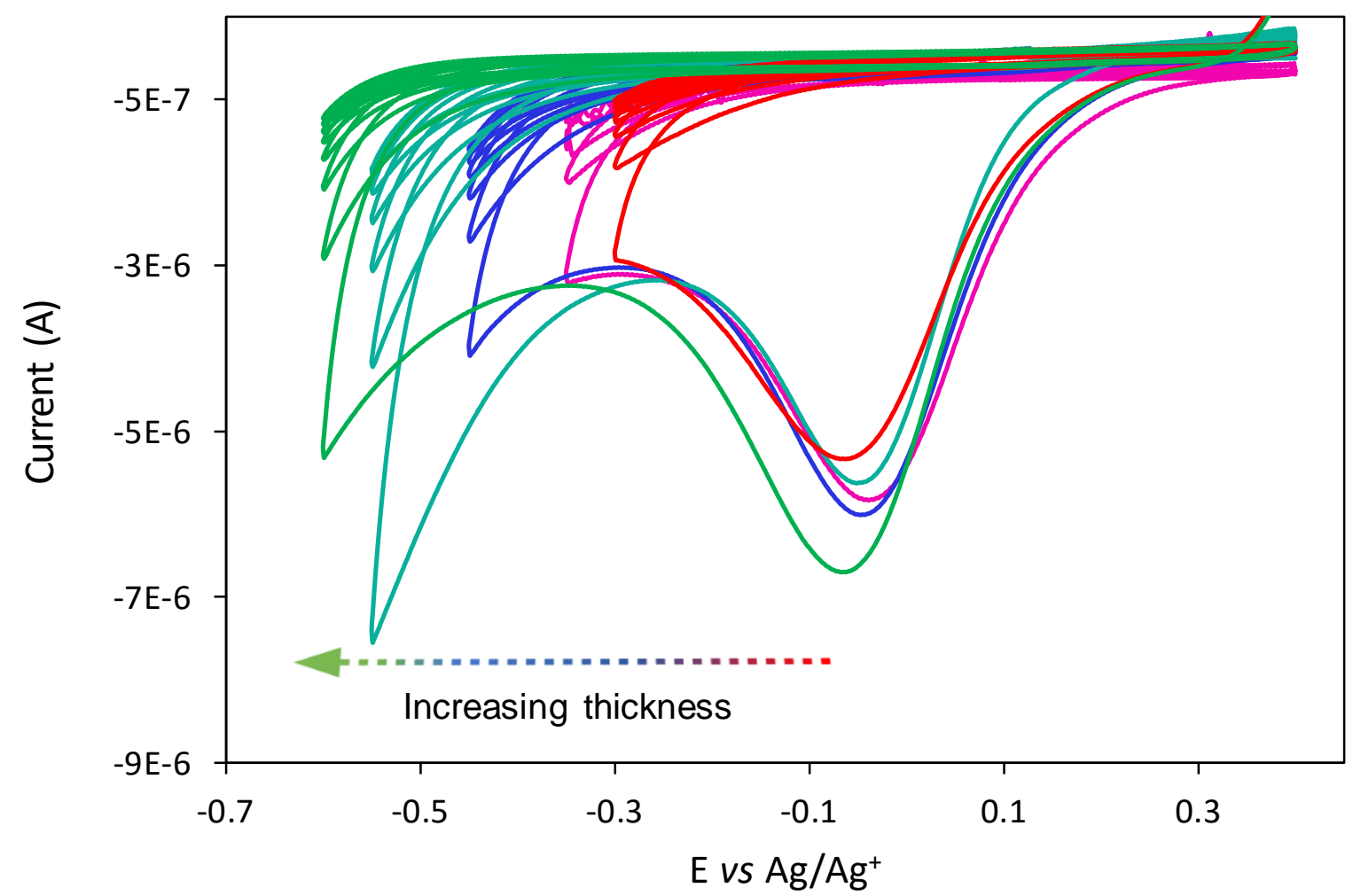

Figure S2. Cyclic voltammogram grafting of Anthraquinone on the surface of $\mathrm{Cr}_{3} / \mathrm{Au}_{15} / \mathrm{eC}_{10}$. 


\subsubsection{Cr/Au modification}

The parameters used for grafting of molecular layer on the surface of $\mathrm{Cr} / \mathrm{Au}$ electrode are listed in Table S3 and corresponding cyclic voltammograms are shown in Figure S3.

Table S3. Anthraquinone grafting parameters on $\mathrm{Cr}_{3} / \mathrm{Au}_{15}$ surfaces

\begin{tabular}{|c|c|c|c|c|}
\hline $\begin{array}{c}\text { Anthraquinone } \\
\text { Grafting }\end{array}$ & $\begin{array}{c}\text { Sweep range } \\
\left(\mathrm{E} v \text { s. Ag/ } \mathrm{Ag}^{+}\right)\end{array}$ & $\begin{array}{c}\text { No. of } \\
\text { cycles }\end{array}$ & $\begin{array}{c}\text { Scan rate } \\
(\mathrm{mV} / \mathrm{s})\end{array}$ & $\begin{array}{c}\text { Thickness } \\
(\mathrm{nm})\end{array}$ \\
\hline Sample 1 & $0.4-(-0.35)$ & 6 & 50 & $3.1 \pm 0.42$ \\
\hline Sample 2 & $0.4-(-0.45)$ & 6 & 50 & $4.2 \pm 0.50$ \\
\hline Sample 3 & $0.4-(-0.55)$ & 6 & 50 & $5.2 \pm 0.53$ \\
\hline
\end{tabular}

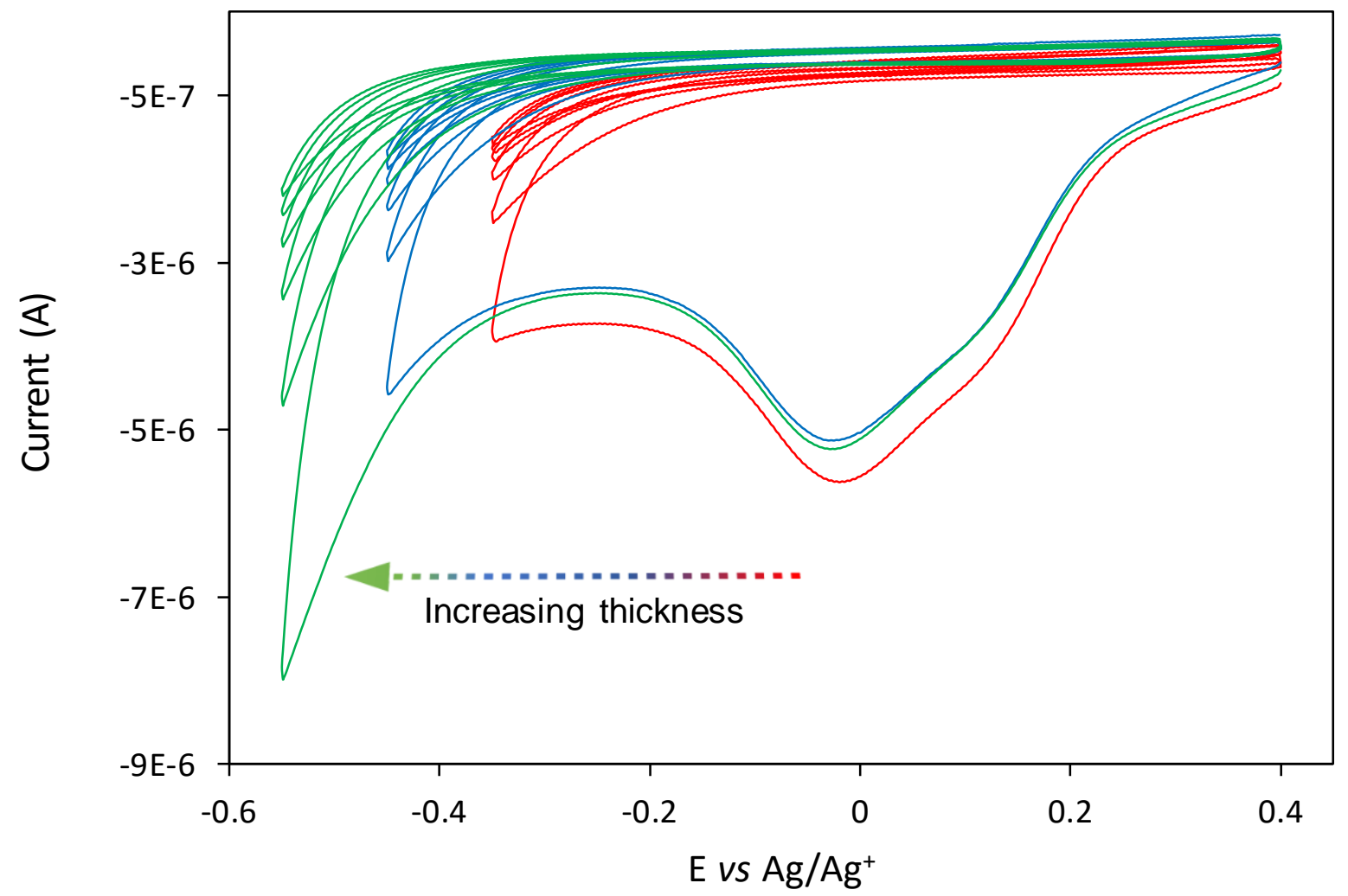

Figure S3. Cyclic voltammogram grafting of Anthraquinone on the surface of $\mathrm{Cr}_{3} / \mathrm{Au}_{15}$. 


\subsection{Top contact deposition}

The top contact electrode was comprised of electron beam deposition of $10 \mathrm{~nm} \mathrm{eC}$ and 15 $\mathrm{nm} \mathrm{Au}$ through a physical shadow mask with $0.25 \mathrm{~mm}$ openings oriented perpendicular to the bottom contact, which results in a crossbar junction of $0.062 \mathrm{~mm}^{2}$ area.

\section{3 eC electrode characterization}

$\mathrm{eC}$ is presumably formed by carbon atoms and clusters striking a solid surface and rapidly forming a variety of bonds to adjacent particles, thus forming an amorphous mixture of $\mathrm{sp}^{1}, \mathrm{sp}^{2}$ and $\mathrm{sp}^{3}$ hybridization. The work function of $\mathrm{eC}$ determined by extrapolation of the high energy region of the Ultraviolet Photoelectron Spectrum for four separate samples yielded 4.80, 4.80, $4.82,4.92 \mathrm{eV}$, for an average of $4.83 \pm 0.06 \mathrm{eV}$, and did not change significantly when eC was deposited on $\mathrm{SiOx}$ or $\mathrm{SiOx} / \mathrm{Cr} / \mathrm{Au}$. Although the detailed structure of eC is both complex and disordered, Raman spectroscopy and X-ray photoelectron spectroscopy (XPS) provide estimates of $\mathrm{sp}^{3}$ content.

\subsection{Raman spectroscopy}

Interpretation of Raman spectra of amorphous carbon to determine hybridization and bonding geometry has been described ${ }^{3,4}$. In the current experiments, a custom-built spectrometer consisting of an $\mathrm{Ar}^{+}$ion laser $(514.5 \mathrm{~nm})$, a $50 \mathrm{~mm} \mathrm{f} / 1.8$ collection lens, a holographic reflection grating (2000 grove/mm), and an Andor back-thinned CCD detector cooled to $-80^{\circ} \mathrm{C}$ was used to acquire the spectra ${ }^{5}$. Raman shift was calibrated with naphthalene and polystyrene. As suggested in the literature, Breit-Wigner-Fano (BWF) fitting for the G peak and a Lorentzian for the D peak results in the excellent deconvolution for all carbon Raman with low residuals ${ }^{4}$. The relative positions of the $\mathrm{D}$ and $\mathrm{G}$ bands following deconvolution were used to estimate the $\% \mathrm{sp}^{3}$ content according to the procedure of Ferrari and Robertson ${ }^{4}$. Raman spectra and deconvolutions of 
spectra to D and G peaks of different type of carbon are shown in Figure S4 to S7, including the with the estimated $\mathrm{sp}^{3}$ content indicated for each case.

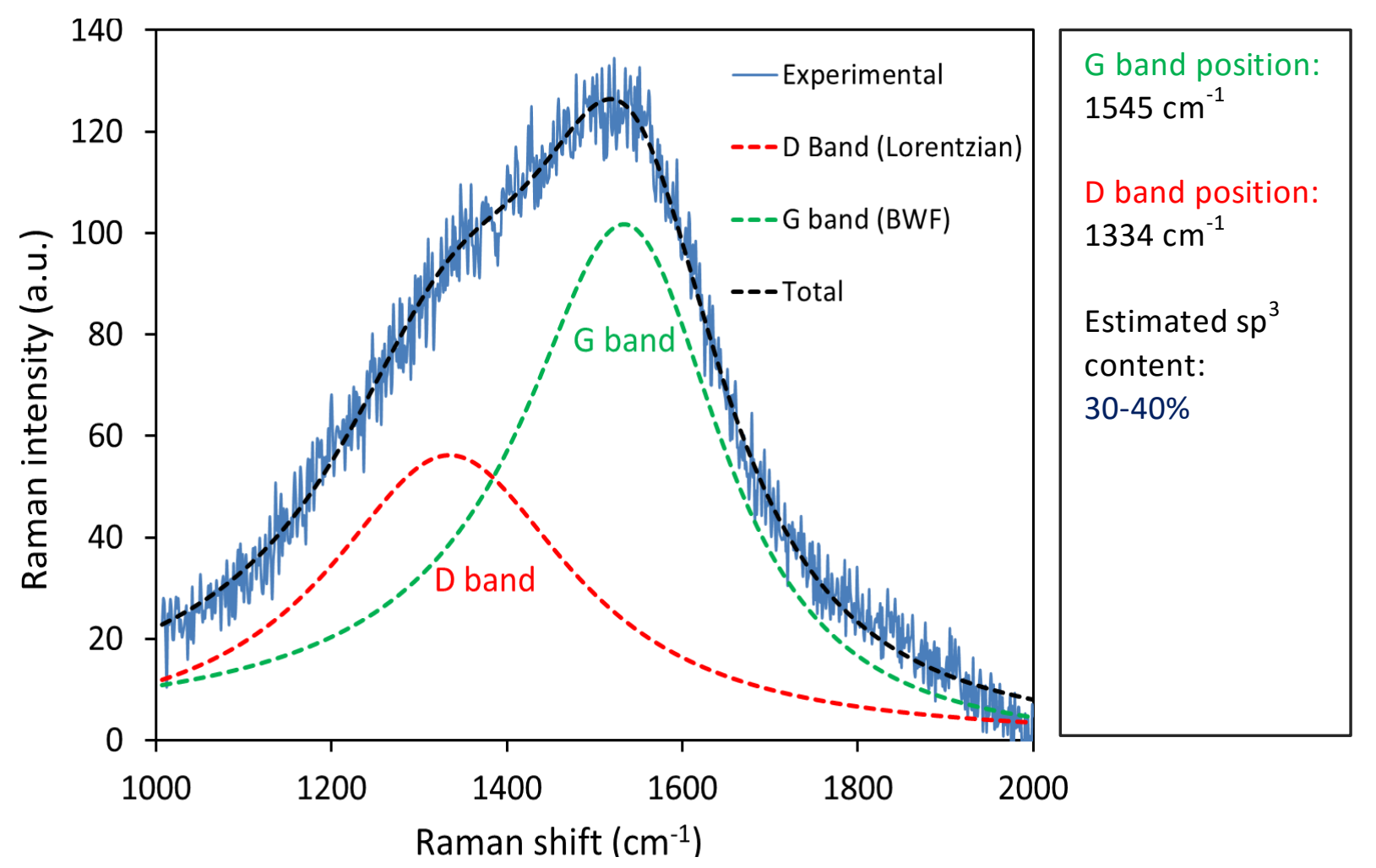

Figure S4. Raman spectrum of electron-beam deposited carbon $(\mathrm{eC})$. 


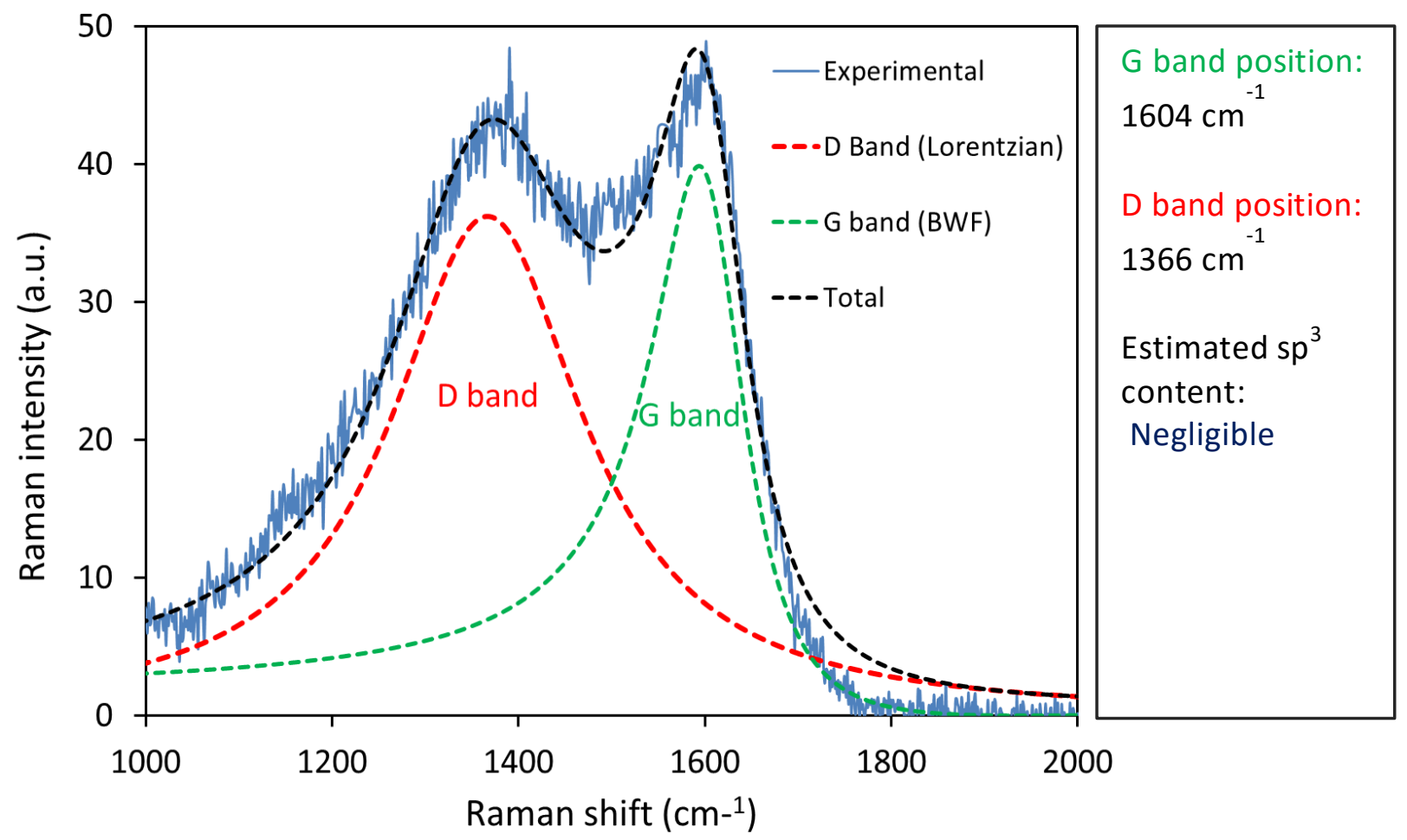

Figure S5. Raman spectra of eC after 3 Hours annealing at $1000{ }^{\circ} \mathrm{C}$ in forming gas

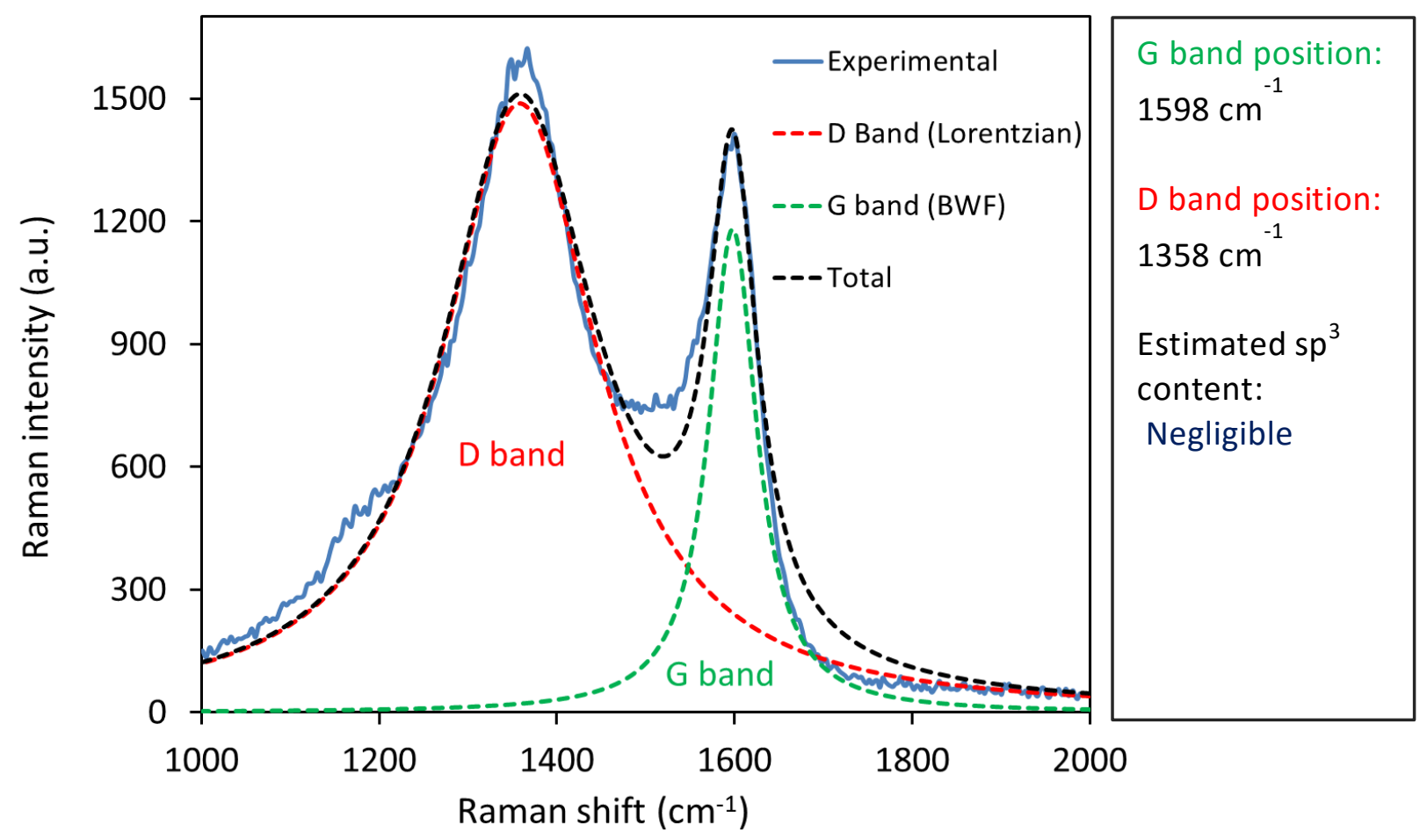

Figure S6. Raman spectra of pyrolyzed photoresist (PPF). 


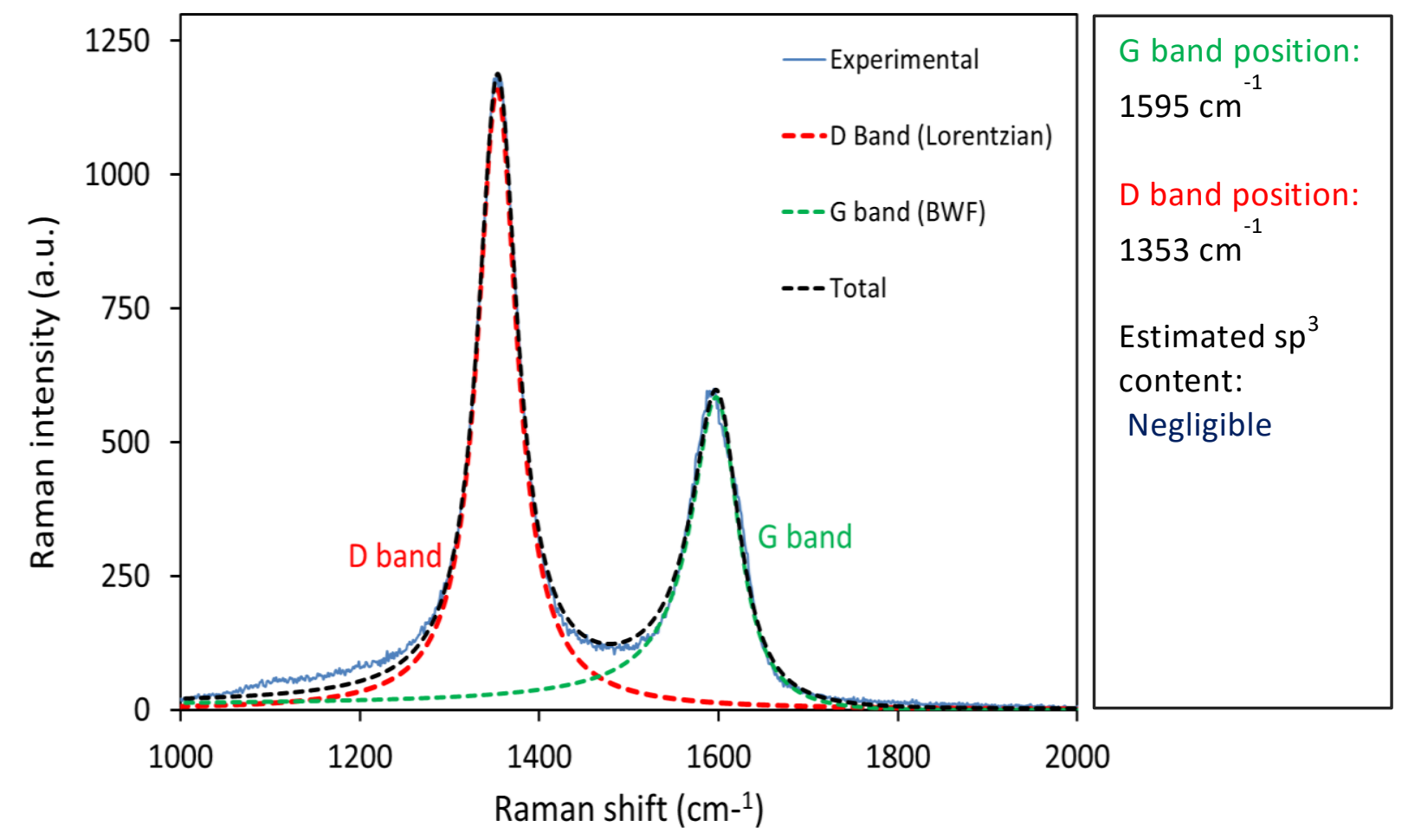

Figure S7. Raman spectra of glassy carbon (GC).

\subsection{XPS}

X-ray photoelectron spectroscopy (XPS) has also been used to estimate $\mathrm{sp}^{3}$ content, by a deconvolution approach described by Jackson and Nuzzo ${ }^{6}$ and Jia, et al. ${ }^{7}$. XPS analyses were acquired with an AXIS 165 spectrometer equipped with a monochromatic Al Ka source (1486.6 $\mathrm{eV})$. XPS of as as-deposited $\mathrm{eC}$ and the same $\mathrm{eC}$ film after 3 hours annealing in $1000{ }^{\circ} \mathrm{C}$ are shown in Figure S8 and S9 respectively, along with the estimated $\% \mathrm{sp}^{3}$ content. 


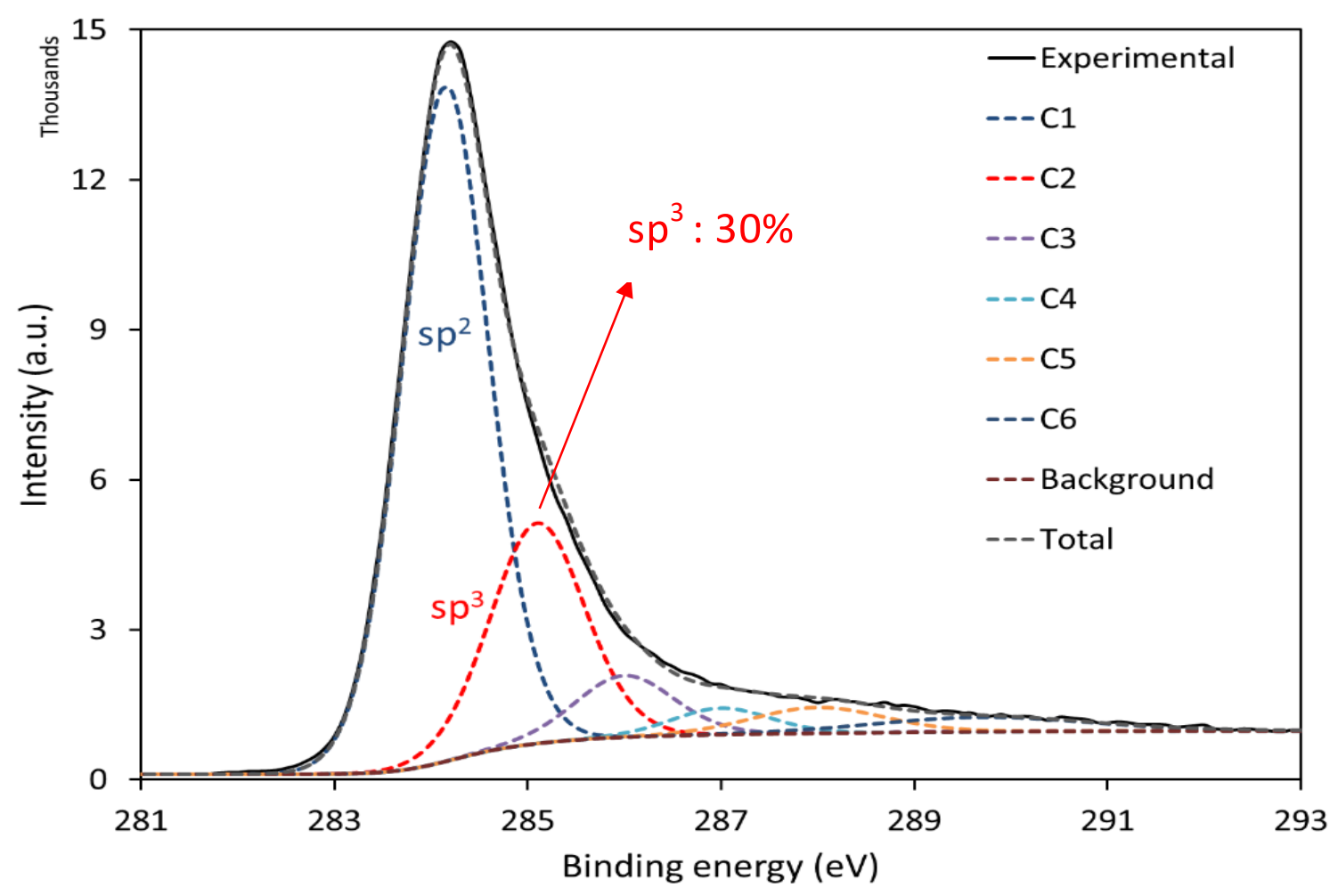

Figure S8. XPS C 1s region of electron beam deposited carbon $(\mathrm{eC})$.

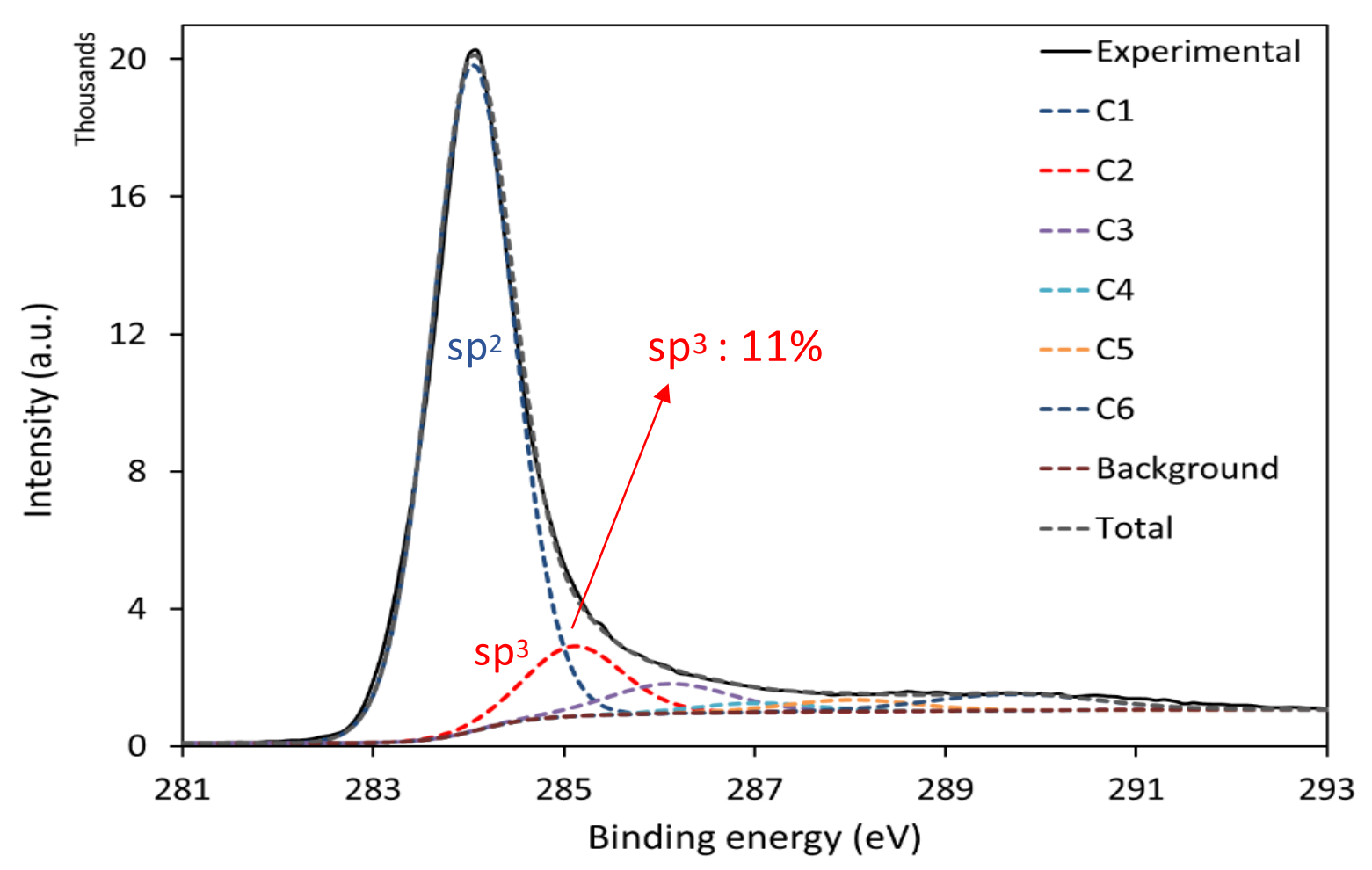

Figure S9. XPS C 1 s region of eC after 3 hours annealing at $1000{ }^{\circ} \mathrm{C}$. 


\section{Electrical Measurement}

Current-voltage curves were obtained using a Keithley 2602A source-measurement unit or a custom-built LabVIEW measurement system that has been described previously ${ }^{1}$. All electrical measurements were done using 4-wire mode unless indicated otherwise.

\subsection{Two- and Four-wire mode measurement}

Four-wire mode measurement can be used to compensate contact resistance and internal ohmic losses in the PPF or eC films; however, many laboratory and practical applications use a two-wire geometry. Two- and four-wire mode measurements for molecular junctions made with $\mathrm{PFF}$ and $\mathrm{Cr} / \mathrm{Au} / \mathrm{eC}$ substrate electrodes are compared in Figure S10 and S11, respectively. In the case of PPF, the relatively high resistance of the PPF substrate distorts the 2-wire measurement due to ohmic potential losses (Figure S10). Since the sheet resistance of $\mathrm{Au} / \mathrm{eC}$ is at least a factor of ten lower than that of PPF (Table 1 in main text), much less distortion is observed. (Fig. S11). The small error apparent in Figure S11 is likely due to the contact resistance between the tungsten probes and the $\mathrm{Au}$ contact points or the residual resistance of the $\mathrm{Au}_{30}$ film, and is completely compensated using 4-wire geometry. 


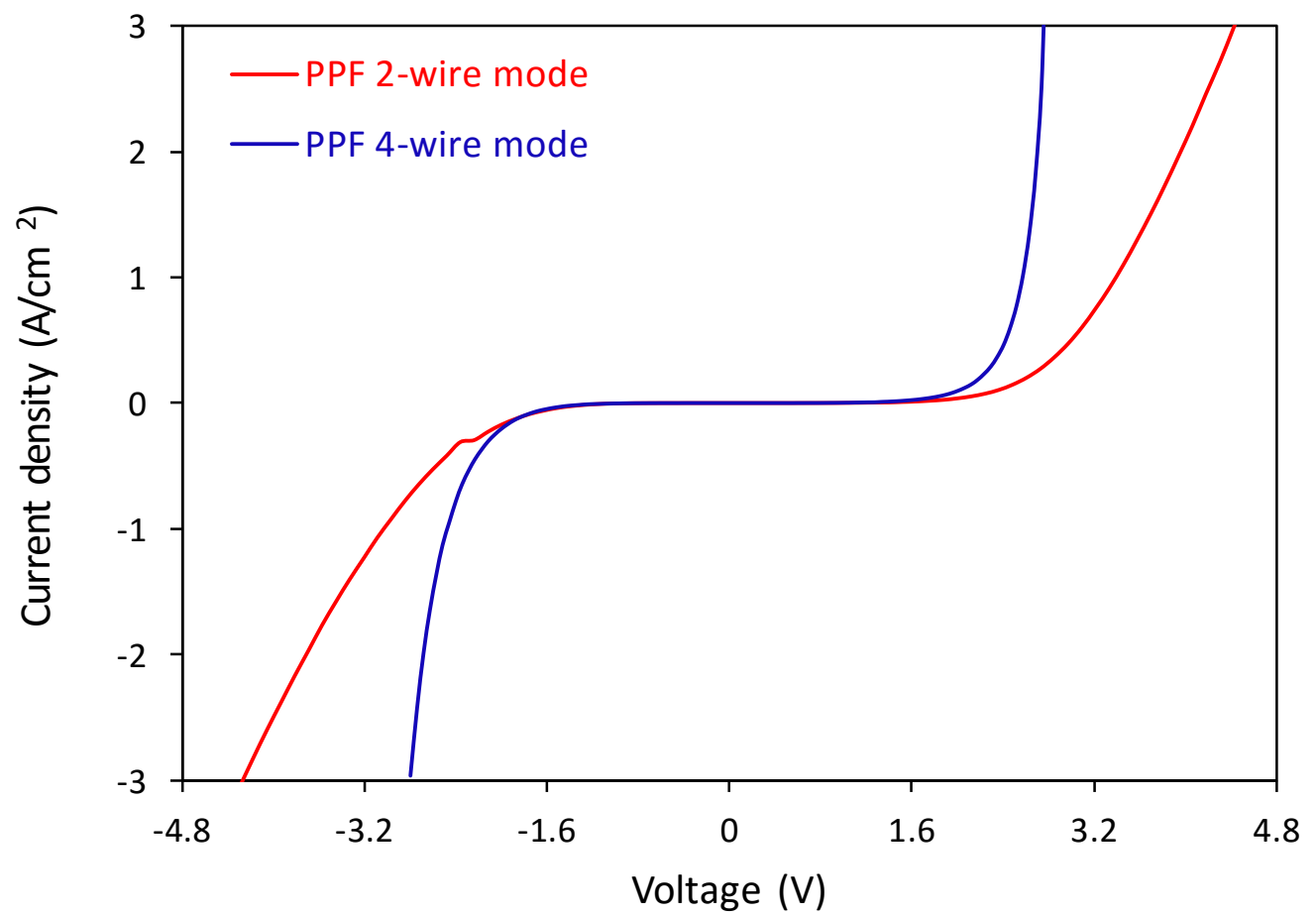

Figure S10. Comparison of two- and four-wire mode measurement for PPF// NAB //eC/Au.

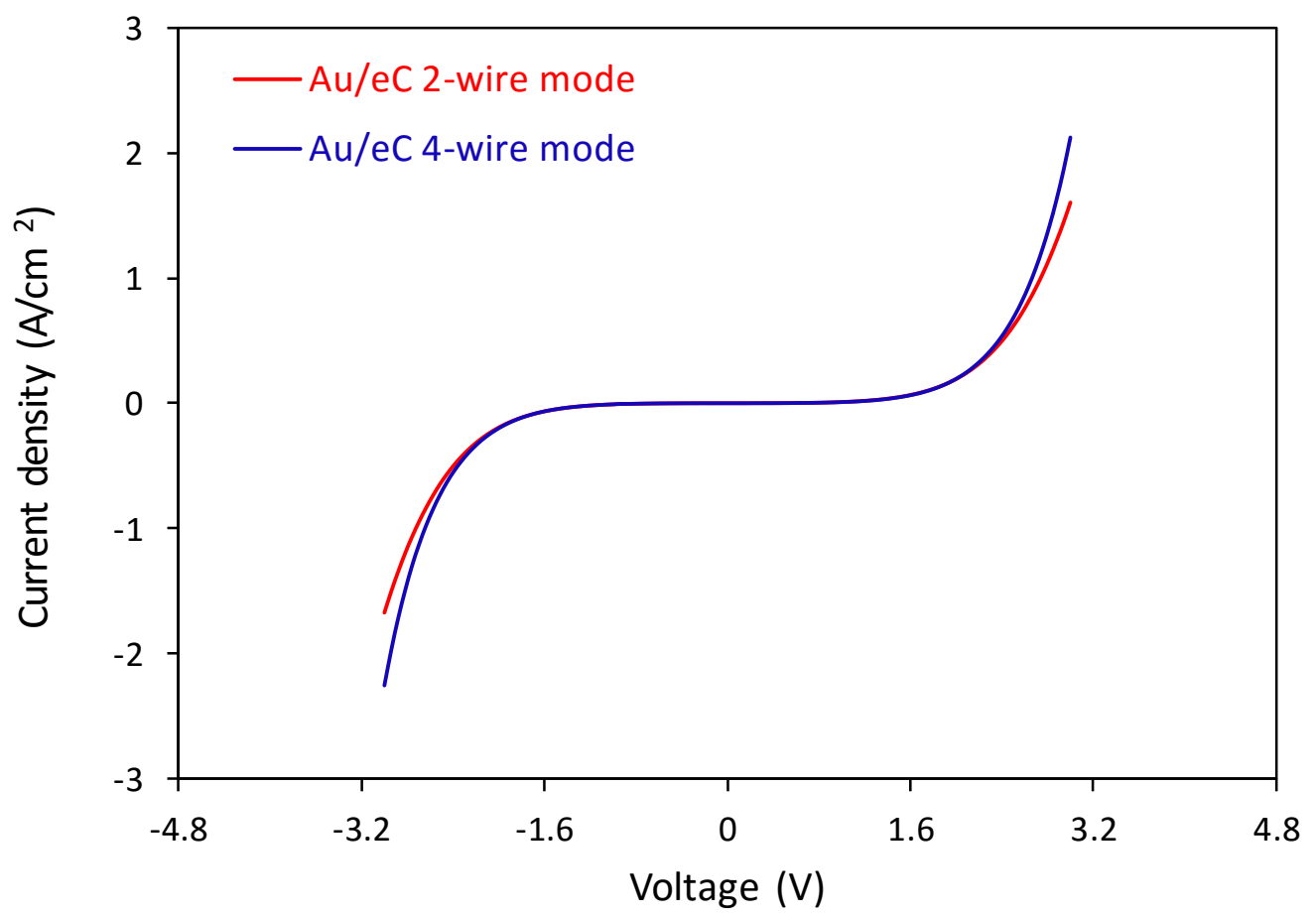

Figure S11. Comparison of two- and four-wire mode measurement for $\mathrm{Cr}_{3} / \mathrm{Au}_{30} / \mathrm{eC}_{10} /$ $\mathrm{NAB} / \mathrm{eC}_{10} / \mathrm{Au}_{20}$ in the integrated design shown in Figure 8 of the main text. 


\subsection{Arrhenius plot for $\mathrm{eC} / \mathrm{AQ} / \mathrm{eC}$ junction}

The Arrhenius plot for the temperature dependence of the JV curves shown in Figure 5c in the main text is shown in Figure S12. Also, approximate activation energies in different ranges of temperature are indicated.

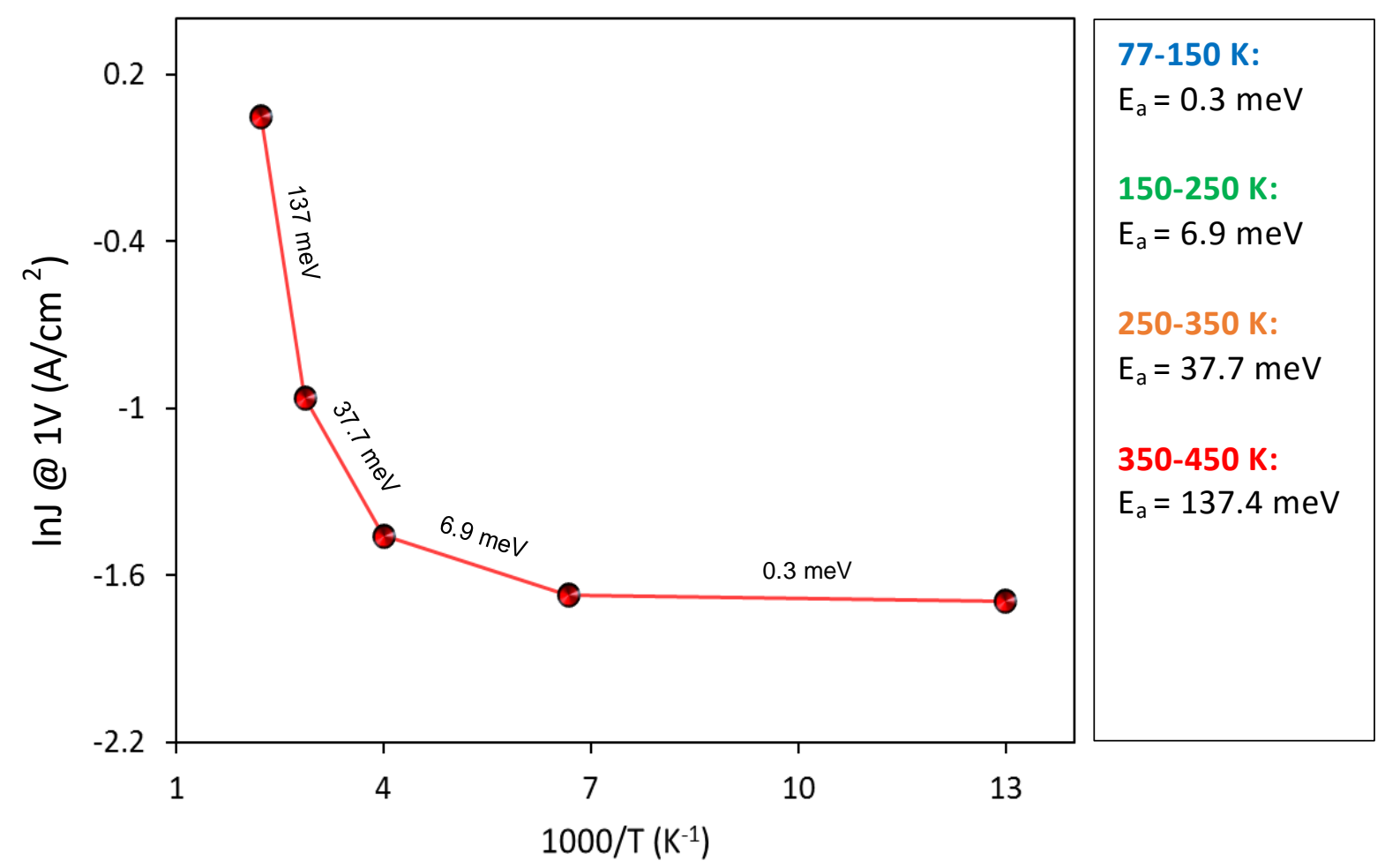

Figure S12. Arrhenius plot for $\mathrm{Cr}_{3} / \mathrm{Au}_{15} / \mathrm{eC}_{10} / \mathrm{AQ}_{4.5} / \mathrm{eC} \mathrm{C}_{10} / \mathrm{Au}_{15}$ molecular junction.

\section{Statistics}

Error bars in $J V$ plots in Figure 4 of the main text are standard deviations of current density for all 8 junctions on a given chip, with yield for all five samples being $100 \%$ of non-shorted junctions. An example of the raw data set for $\mathrm{Cr}_{3} / \mathrm{Au}_{15} / \mathrm{eC}_{10} / \mathrm{AQ} / / \mathrm{eC}_{10} / \mathrm{Au}_{15}$ junctions is shown in Figure S13, which is an overlay of $I V$ curves in linear and semi-logarithmic scale for eight different junctions with an AQ thickness of $3.8 \mathrm{~nm}$. The RSD of current for the eight junctions 
shown varies from $18 \%$ at $1.4 \mathrm{~V}$ to $27 \%$ at $0.1 \mathrm{~V}$. In the case of $\mathrm{Cr} / \mathrm{Au}$ bottom electrode, the yield was lower than $50 \%$ (i.e. > 50\% shorted) and standard deviations exceeded $50 \%$, as indicated by the error bars in Figure 4c. Yields and relative standard deviations for the five examples shown in Figure $4 \mathrm{a}$ of the main text are listed in Table S4.

Table S4. $J V$ Statistics of $\mathrm{SiOx} / \mathrm{Cr} / \mathrm{Au} / \mathrm{eC} / \mathrm{AQ} / \mathrm{eC} / \mathrm{Au}$ junctions

\begin{tabular}{|c|c|c|c|c|c|}
\hline Thickness (nm) & Yield $^{a}$ & Bias (V) & $\begin{array}{c}\text { Mean J @ V } \\
\left(\mathrm{A} / \mathrm{cm}^{2}\right)\end{array}$ & $\begin{array}{c}\text { Standard } \\
\text { deviation of J }\end{array}$ & RSD (\%) \\
\hline $2.3 \pm 0.25$ & $8 / 8$ & 0.3 & 2.6 & 0.46 & 28 \\
\hline $2.9 \pm 0.35$ & $8 / 8$ & 0.6 & 2.9 & 0.85 & 20 \\
\hline $3.8 \pm 0.27$ & $8 / 8$ & 1.0 & 2.1 & 0.41 & 21 \\
\hline $4.5 \pm 0.28$ & $8 / 8$ & 1.5 & 2.0 & 0.67 & 28 \\
\hline $5.1 \pm 0.32$ & $8 / 8$ & 1.9 & 2.2 & 45 \\
\hline
\end{tabular}

a. yield indicates the number of the junction with no evidence of direct eC/eC contact (a "short") 

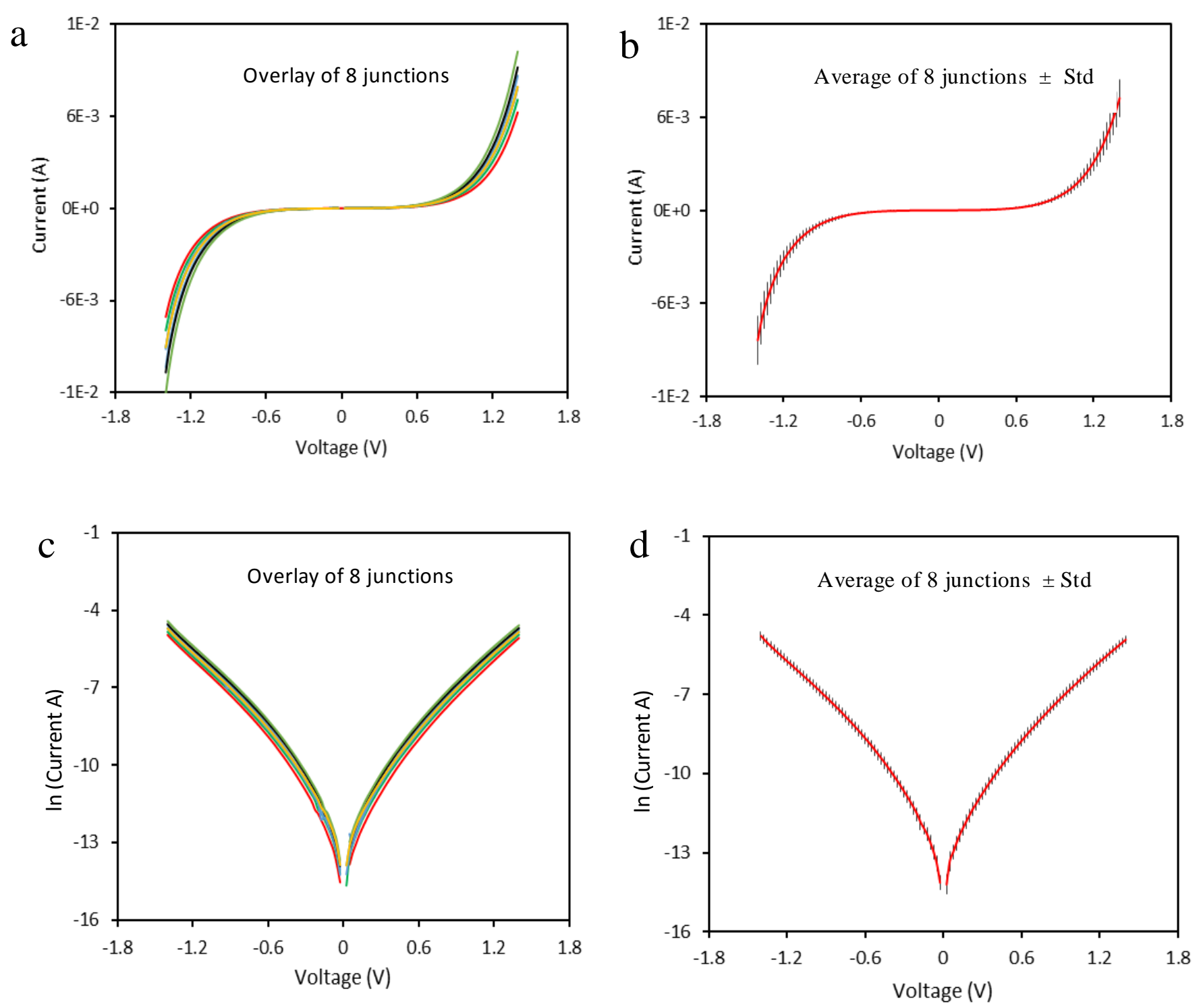

Figure S13. Statistics for $\mathrm{Cr}_{3} / \mathrm{Au}_{15} / \mathrm{eC}_{10} / \mathrm{AQ}_{3.8} / \mathrm{eC}_{10} / \mathrm{Au}_{15}$ junctions a) Overlay of eight measured $I V$ curves b) Average of eight $I V$ curves \pm standard deviation c) Overlay of eight $\ln (I)$ versus voltage d) Average of eight $\ln (I)$ versus voltage \pm standard deviation.

\section{Photolithographic integrated chip design}

The integrated chip shown in Figure 8 of the main text was developed to provide a standard substrate that would permit a wider range of device sizes than those available using a shadow mask to deposit the bottom $\mathrm{Au} / \mathrm{eC}$ electrode. It also provides electrical isolation of the junctions, a 
single, common contact for electrochemical surface modification, and probe contact pads of $\mathrm{Au}$ rather than eC. Details of the fabrication are as follows:

I. 4" silicon (100) wafer substrates with $300 \mathrm{~nm}$ of thermally grown silicon oxide were used as the base substrates. Substrates were cleaned using a hot piranha solution (concentrated $\mathrm{H}_{2} \mathrm{SO}_{4}: 30 \%$ $\mathrm{H}_{2} \mathrm{O}_{2}, 3: 1 \mathrm{v} / \mathrm{v}$ ) for $15 \mathrm{~min}$ and rinsed with deionized water before drying. [Warning: piranha solution is extremely dangerous] A bilayer photoresist stack was spin-coated onto the wafers. First, LOR 0.7A resist (MicroChem) was spun on at $200 \mathrm{rpm}$ for 10 seconds followed by 2000 rpm for 45 seconds. The wafer was then baked for 2 minutes on a hot plate for $170^{\circ} \mathrm{C}$. The top layer resist, HPR 504 (MicroChem), was spun on at $500 \mathrm{rpm}$ for 10 seconds followed by $400 \mathrm{rpm}$ for 45 seconds and soft baked for 90 seconds at $115^{\circ} \mathrm{C}$ on a hot plate. Wafers were allowed to rehydrate for 15 minutes before being patterned using a photomask and UV exposure. Exposed wafers were developed in MF-26A developer (Microposit) for approximately 40 seconds under gentle agitation until fully developed. Fully developed wafers were rinsed with deionized water and dried with nitrogen.

II. Patterned wafers are loaded into a Johnson Ultravac (JUV) e-beam deposition system for metal deposition of $\mathrm{Cr}_{4} / \mathrm{Au}_{30}$. The system is pumped down to a base pressure prior to deposition of $4 \times 10^{-}$ ${ }^{7}$ torr. After the metal deposition, the chamber is vented and a shadow mask is aligned and attached to each individual wafer for the $\mathrm{eC}_{10}$ deposition in order to selectively coat the wafers. The JUV has pumped down again and the $10 \mathrm{~nm}$ of e-beam carbon is evaporated. An addition coating of HPR 504, same parameters, is spun onto the wafers as a barrier layer to protect the samples from the atmosphere and dicing saw residue. The wafers are diced using a Disco DAD 321 dicing saw into individual die chips of $13 \mathrm{~mm}$ x $18.5 \mathrm{~mm}$ which can be stored until use. 
III. In order to prepare the chips for electrochemistry, diced chips are immersed in dimethyl sulfoxide (Fisher certified ACS) for 1 hour to lift-off the photoresist layers. The chips are held in either an upright position or device layer down depending on the holder to ensure that any metal or dicing particles coming off the sample during lift-off do not fall back onto the surface of the chips. Chips are then sonicated in fresh DMSO, DI water, and IPA for 10 minutes each as a final clean prior to electrochemistry.

IV. Electrochemical procedure for grafting of molecular layer was the same as described in section 2.2. Nitro-azobenzene (NAB) diazonium fluoroborate salt $(1 \mathrm{mM})$ was used for grafting of the molecular layer. Grafting parameters are listed in Table S4 and corresponding cycling voltammetry is shown in Figure S14.

Table S4. Electrochemical grafting parameters for NAB on integrated chips

\begin{tabular}{|c|c|c|c|c|}
\hline NAB Grafting & $\begin{array}{c}\text { Sweep range } \\
\left(\mathrm{E} v \text {. Ag/Ag }{ }^{+}\right)\end{array}$ & $\begin{array}{c}\text { No. of } \\
\text { cycles }\end{array}$ & $\begin{array}{c}\text { Scan rate } \\
(\mathrm{m} \text { V/s })\end{array}$ & $\begin{array}{c}\text { Thickness } \\
(\mathrm{nm})\end{array}$ \\
\hline Sample 1 & $0.4-(-0.20)$ & 4 & 100 & $3.6 \pm 0.24$ \\
\hline Sample 2 & $0.4-(-0.40)$ & 4 & 100 & $4.1 \pm 0.29$ \\
\hline Sample 3 & $0.4-(-0.60)$ & 4 & 100 & $4.8 \pm 0.31$ \\
\hline Sample 4 & $0.4-(-0.80)$ & 4 & 100 & $6.2 \pm 0.43$ \\
\hline
\end{tabular}




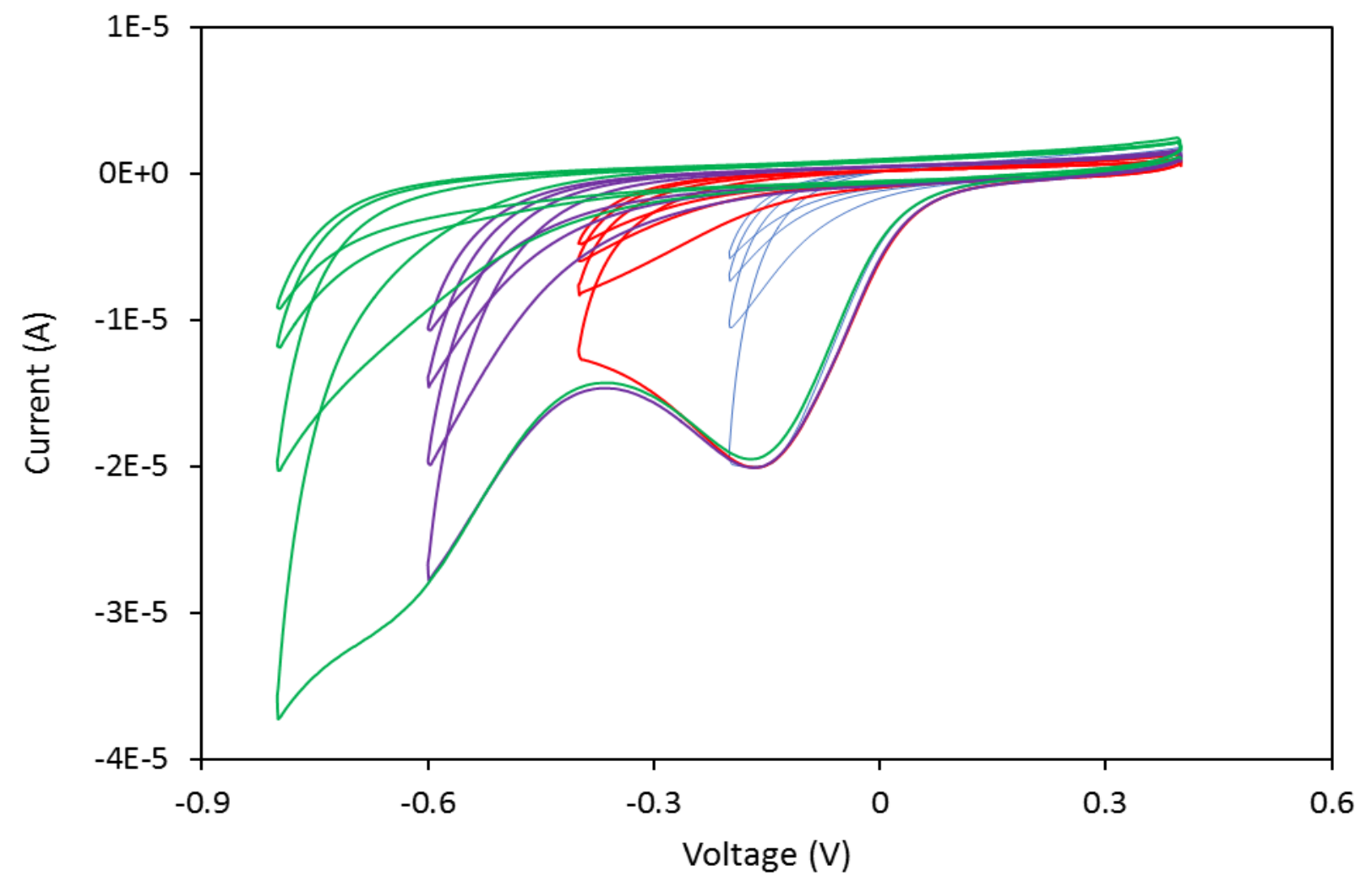

Figure S14. Cyclic voltammograms of grafting Nitro-azobenzene (NAB) on the surface of integrated $\mathrm{Cr}_{4} / \mathrm{Au}_{30} / \mathrm{eC}_{10}$ chips in acetonitrile solution of $1 \mathrm{mM}$ NAB and $0.1 \mathrm{M}$ TBAPF6.

$\mathbf{V}$. The procedure for top contact deposition was the same as described in section 2.3, except the Au thickness was increased to $20 \mathrm{~nm}$ since transparency was not required.

VI. Electrical measurements were done as described in section 4. Yields and relative standard deviations for the four examples shown in Figure 8d of the main text are listed in Table S5. 
Table S5. Statistics of integrated $\mathrm{Cr}_{4} / \mathrm{Au}_{30} / \mathrm{eC}_{10} / \mathrm{NAB} / \mathrm{eC}_{10} / \mathrm{Au}_{20}$ junctions

\begin{tabular}{|c|c|c|c|c|c|}
\hline $\begin{array}{c}\text { NAB Thickness } \\
(\mathrm{nm})\end{array}$ & Yield & Voltage (V) & $\begin{array}{c}\text { Mean J @ V } \\
\left(\mathrm{A} / \mathrm{cm}^{2}\right)\end{array}$ & $\begin{array}{c}\text { Standard } \\
\text { deviation of J }\end{array}$ & RSD (\%) \\
\hline $3.6 \pm 0.24$ & $6 / 6$ & 0.4 & 2.1 & 0.19 & 14 \\
\hline $4.1 \pm 0.29$ & $6 / 6$ & 0.9 & 2.3 & 0.3 & 22 \\
\hline $4.8 \pm 0.31$ & $8 / 8$ & 1.3 & 2.7 & 0.6 & 6 \\
\hline $6.2 \pm 0.43$ & $8 / 8$ & 2 & 2.3 & 0.15 & 6 \\
\hline
\end{tabular}

a. yield indicates the number of the junction with no evidence of direct eC/eC contact (a "short")

\section{References:}

(1) Ru, J.; Szeto, B.; Bonifas, A.; McCreery, R. L. Microfabrication and Integration of Diazonium-Based Aromatic Molecular Junctions. ACS Appl. Mater. Interfaces 2010, 2, 36933701.

(2) Sayed, S. Y.; Fereiro, J. A.; Yan, H.; McCreery, R. L.; Bergren, A. J. Charge Transport in Molecular Electronic Junctions: Compression Of The Molecular Tunnel Barrier In The Strong Coupling Regime. Proc. Natl. Acad. Sci. U. S. A. 2012, 109, 11498-11503.

(3) Robertson, J. Diamond-Like Amorphous Carbon. Mater. Sci. Eng. R. 2002, 37, 129-281.

(4) Ferrari, A. C.; Robertson, J. Interpretation of Raman Spectra of Disordered and Amorphous Carbon. Phys. Rev. B 2000, 61, 14095-14107.

(5) Ramsey, J. D.; Ranganathan, S.; Zhao, J.; McCreery, R. L. Performance Comparison of Conventional and Line-Focused Surface Raman Spectrometers. Appl. Spectrosc. 2001, 55, 767773.

(6) Jackson, S. T.; Nuzzo, R. G. Determining Hybridization Differences for Amorphous Carbon From The XPS C 1s Envelope. Appl. Surf. Sci. 1995, 90, 195-203.

(7) Jia, J.; Kato, D.; Kurita, R.; Sato, Y.; Maruyama, K.; Suzuki, K.; Hirono, S.; Ando, T.; Niwa, O. Structure and Electrochemical Properties of Carbon Films Prepared by a Electron Cyclotron Resonance Sputtering Method. Anal. Chem. 2007, 79, 98-105. 